\title{
First report of Babesia gibsoni in Central America and survey for vector-borne infections in dogs from Nicaragua
}

\author{
Lanjing Wei ${ }^{1,2}$, Patrick Kelly ${ }^{3}$, Kate Ackerson ${ }^{3}$, Jilei Zhang ${ }^{1,2}$, Heba S El-Mahallawy ${ }^{1,4}$, Bernhard Kaltenboeck ${ }^{5}$ \\ and Chengming Wang ${ }^{1,2^{*}}$
}

\begin{abstract}
Background: Although many vector-borne diseases are important causes of morbidity and mortality in dogs in tropical areas and potential zoonoses, there is little information on these conditions in Central America.

Methods: Seven qPCRs for vector-borne pathogens were performed on a Roche LightCycler PCR Instrument to investigate their prevalence in a convenience sample of whole blood samples from apparently healthy dogs in Nicaragua. Also, a qPCR targeting the canine hydroxymethylbilane synthase (HMBS) gene was used as an endogenous internal control and verified the quality and quantity of DNA in the samples was appropriate for the study.

Results: We found DNA of Rickettsia felis (5\%), Babesia spp. (26\%), Hepatozoon canis (51\%), Anaplasma platys (13\%) and Ehrlichia canis (56\%) in the 39 dogs studied. The gPCRs for Coxiella burnetii and Dirofilaria immitis were negative. Of the $30(80 \%)$ dogs that were positive by qPCR, 12 (31\%) were positive for one agent, 11 (28\%) for two, 3 (8\%) for three, and 4 (10\%) for four agents.

Conclusions: This is the first report of B. gibsoni in dogs from Central America and the first recording of vector-borne agents in dogs from Nicaragua. Dogs in Nicaragua are commonly infected with a variety of vector-borne pathogens, some of which may also infect people.
\end{abstract}

Keywords: Nicaragua, Rickettsia felis, Babesia gibsoni/vogeli, Hepatozoon canis, Anaplasma platys, Ehrlichia canis, Coxiella burnetii, Dirofilaria immitis

\section{Background}

Vector-borne agents are important causes of morbidity and mortality in dogs worldwide [1-4]. Many cause zoonoses and the close relationship between people and their dogs facilitates human infections. Knowledge of the prevalences of canine vector-borne disease is thus important for veterinarians and their patients as well as for workers in the public health field [5]. There is only very limited data on vector-borne diseases in dogs from the seven Central American states with reports from only three countries, mainly Costa Rica [6-8], Panama [9-11] and Guatemala [12]. To provide further data on canine

\footnotetext{
*Correspondence: chengmingwang@gmail.com

'Yangzhou University College of Veterinary Medicine, Yangzhou, Jiangsu, P. R. China

${ }^{2}$ Jiangsu Co-innovation Center for the Prevention and Control of Important Animal Infectious Diseases and Zoonoses, Yangzhou, Jiangsu, P. R. China Full list of author information is available at the end of the article
}

vector-borne diseases from the region, we investigated a convenience sample of dogs from Nicaragua and describe the findings in this report.

\section{Methods}

Dogs and blood samples

This study was approved by the Institutional Animal Care and Use Committee of the Yangzhou University College of Veterinary Medicine of China. Convenience samples of whole blood were collected into EDTA from 39 apparently healthy dogs presented at a neutering program operated by Volunteers for Intercultural and Definitive Adventure (VIDA, sites.google.com/site/rusvmvida) in April 2012. The dogs belonged to local people from underprivileged areas in Rivas, a city situated in Southwestern Nicaragua. Verbal permission was received from the owners of the dogs for blood to be used in the study. The whole blood 
samples were stored at $4^{\circ} \mathrm{C}$ for $2-3$ days before aliquots $(200 \mu \mathrm{L})$ were frozen at $-80^{\circ} \mathrm{C}$ until DNA was extracted as described below.

\section{DNA extraction}

The High-Pure PCR Template Preparation Kit (Roche Molecular Biochemicals, Indianapolis, IN, USA) was used to extract total nucleic acids from the whole blood aliquots as described previously [13]. Each extracted DNA was eluted in $200 \mu \mathrm{L}$ elution buffer and stored at $-80^{\circ} \mathrm{C}$ for qPCRs.

\section{Quantitative PCRs}

Eight qPCRs, seven for tick-borne pathogens and one for the canine HMBS gene as an endogenous internal control, were performed on a Roche LightCycler 480-II PCR Instrument. The qPCRs were performed as described previously for R. felis [14], Babesia spp. [15], Hepatozoon spp. [16], Anaplasma spp. [17], E. canis [17], C. burnetii [18] and the canine HMBS gene [19]. The PCR products were verified by gel electrophoresis and nucleotide sequencing using forward and antisense primers (GenScript, Nanjing, China).

The Clustal Multiple Alignment Algorithm was used to compare the GenBank sequences of the 5.8S rRNA of D. immitis (AF217800,EU087700, EU182331.1, EU182328, AF217800)and the following primers and probes were designed specifically for $D$. immitis and validated: sense primer: 5' - TTCAATAACTCTAAGCGGGGGATCACCT3'; anti-sense primer: 5' - TCTGATCGATATTGACCCT CAACCAGAC-3'; 6-FAM probe: 5'-TGCAGACGCATTGAGCACAAAGATTTC-(6-FAM)-3'; LCRed 640 probe: 5' -(LCRed-640)- AATGCACATTGCACCATCGGGTTGA(Phosphate)-3'. The hybridization temperature of the qPCR was found to be optimal at $58^{\circ} \mathrm{C}$ and the thermal cycling protocol was as described previously [17]. A 172-bp nucleotide fragment representing the canine $D$. immitis 5.8S rRNA gene sequence was synthesized and inserted in the pIDTSMART cloning vector (Integrated DNA Technologies, Coralville, IA, USA) and used as the quantitative standard for the D. immitis qPCR. The DNA products were quantified using the PicoGreen ${ }^{\circ}$ DNA fluorescence assay (Molecular Probes, Eugene, OR, USA) and the number of target molecules was calculated. Logarithmic dilutions of the DNA products were used to determine the sensitivity of the $D$. immitis qPCR, which was verified by gel electrophoresis and nucleotide sequencing (GenScript, Nanjing, China).

\section{Statistical analysis}

The gene copy numbers determined by qPCRs were logarithmically transformed for statistical analysis using the Kruskal-Wallis non-parametric ANOVA.

\section{Results and discussion}

The limited time available for the neutering program meant we were unable to carry out detailed investigations of the ticks found on the dogs. The overall impression, however, was that ticks were common and consisted mainly of $R$. sanguineus group. There was no regular use of acaricides for ticks and control was mostly by manual removal when tick burdens were high.

The qPCR for the HMBS gene was positive on all samples with $2.1 \times 10^{6} \pm 8.8 \times 10^{5}$ copies $/ \mathrm{ml}$ whole blood, indicating successful extraction of amplifiable DNA from all samples. The qPCR we developed for D. immitis consistently gave positive results with the quantitative standard we synthesized. Using the standard we found we could detect a single copy of the 5.8S rRNA gene in a qPCR reaction.

We obtained positive qPCR results for 5 of the 7 organisms we tested. Only D. immitis and C. burnetii gave negative qPCR results in all the dogs we examined. $D$. immitis is the agent of canine heartworm disease which is transmitted by mosquitoes and an important cause of lung and heart pathology in dogs worldwide [20]. There is only one report on the disease from Central America where just $2 \%$ of dogs studied in Costa Rica were seropositive [7], considerably less than that from the nearby USA where seroprevalences may be up to $49 \%$ [21]. Absence of animals positive by qPCR in our study could reflect the small sample of dogs we tested or represent a more generalized low level of infection. Further studies are needed to determine the true status of D. immitis infections in Nicaragua.

C. burnetii is the agent of $\mathrm{Q}$ fever in people, a disease reported to occur worldwide, apart from New Zealand [22]. Sources of human infections are generally domestic ruminants although cats have been implicated in some outbreaks [23] and dogs in only one [24]. There are no reports of C. burnetii in people or animals in Central America and we found no evidence of infection in dogs. Using PCR, however, is not a sensitive method to detect C. burnetii exposure in dogs or its presence in an area. In the only other survey for C. burnetii in dog blood which was conducted in Hungary, just 1/123 samples was PCR positive despite 25 being seropositive [25]. To determine the importance of Q fever in Central America, studies are needed on people and livestock which are the major reservoirs of infection.

The most common infectious agent we detected was E. canis $(22 / 39 ; 56 \%)$ with an average of 84 copies of the $16 \mathrm{~S}$ rRNA gene/ml whole blood (SD 71; range $50 \sim 313$ ) (Figure 1). This prevalence is similar to the $47 \%(148 / 310)$ [6] to $34 \%(50 / 146)$ [8] reported from Costa Rica in the only other PCR surveys of dogs in Central America, and these findings suggest the organism is prevalent in the region. Infections with $E$. canis cause canine monocytic 


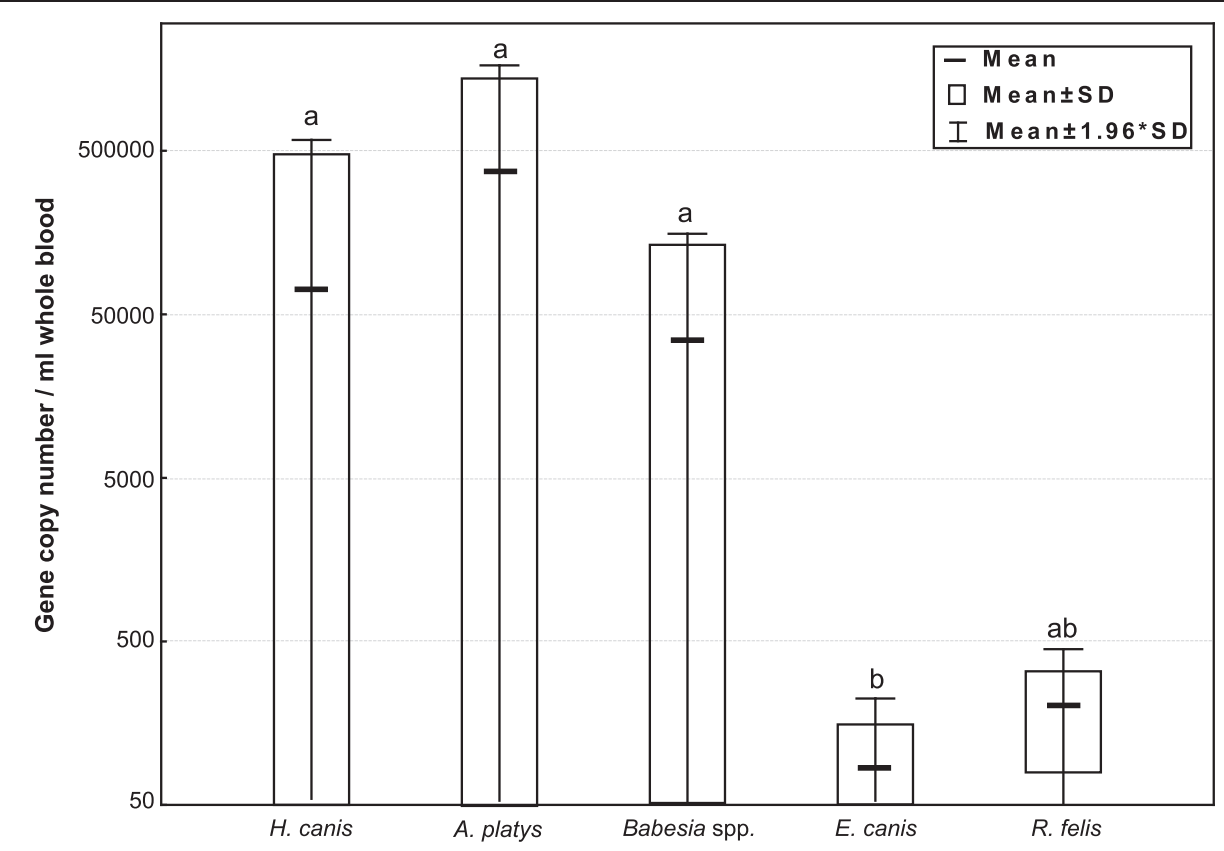

Figure 1 Gene copy number of five vector-borne pathogens in canine whole blood samples. Quantitative FRET-PCRs determined the gene copy number of five tick-borne pathogens. The rRNA copy numbers for $E$. canis ( $84 \pm 71$ /per $\mathrm{ml}$ whole blood; range $50 \sim 313)$ were significantly lower than those for $\mathrm{H}$. canis $(72,120 \pm 260,148)$, A. platys (370472 \pm 659438 ; range $651 \sim 1534409)$, and B. canis $(35161 \pm 61,335 ;$ range $72 \sim 199,552)$. The gltA copy number for $R$. felis (204 \pm 125 ; range 116 and 292) was not significantly different from the rRNA copy number of the other four tick-borne agents. The $Y$-axis is shown as logarithmic scale, and the data were shown as average gene copy number (-), mean \pm SD ( $\square$ ) and mean $\pm 1.96 \times$ SD (I).

ehrlichiosis with $80 \%$ of dogs developing prolonged thrombocytopenia [26,27]. We were unable to carry out hematological examinations on our study dogs but, despite the high likelihood that some were thrombocytopenic, all the surgeries were uneventful and no abnormal bleeding tendencies were noted.

E. canis is transmitted by the Rhipicephalus sanguineus group which occurs worldwide [28]. There is no vaccine for $E$. canis and only tick control can prevent infections. Unfortunately, $R$. sanguineus group is notoriously difficult to control even with expensive modern acaricides and applicators. Diagnosing infections is also challenging as, although organisms can be seen in stained blood smears, microscopy is rarely successful and diagnoses are usually made with expensive serology and/or PCRs. Even when diagnoses are made, treatment failures are common in naturally infected dogs $[17,29]$, most probably as a result of inadequate tick control and re-infection. The difficulties associated with tick control, diagnosis and treatment mean that in underprivileged areas infections with $E$. canis will be particularly difficult to control and canine monocytic ehrlichiosis can be expected to remain prevalent in these areas.

Although apparently uncommon, E. canis can infect people [30] and health workers in Central America should be aware of the high prevalence of ehrlichiosis in dogs and the possibility of infections in their patients, particularly those with a history of tick bites $[8,9,31]$.
Infections with $H$. canis were also very common in our study $(20 / 39 ; 51 \%)$ with an average $18 \mathrm{~S}$ rRNA copy number of 72,120/ml whole blood (SD 260,148; range $3 \sim$ $1,171,720$ ) (Figure 1). A lower infection rate was found in Costa Rica $(11 / 146 ; 8 \%)$ in the only other investigation of the organism in Central America [8]. Infections have also been reported from Africa, Southwestern Asia, Southwestern and Eastern Europe and North and South America [3], indicating a worldwide distribution of the organism. This is expected as the main vector of $H$. canis is $R$. sanguineus group [32], which occurs worldwide [28]. Most infections are subclinical, but in some dogs $(15 \%)$ there is high parasitemia and clinical signs including fever, weight loss, anemia and hyperglobulinemia [33]. Many dogs have concurrent infections with vector-borne agents such as E. canis and Babesia spp., and deciding each agent's contribution to signs is difficult. Various treatments have been used but none are fully effective [34].

The predominant Babesia spp. in dogs are B. gibsoni, B. canis, B. vogeli, and B. rossi [35-37]. In our study we found $26 \%$ of the dogs (10/39) had DNA of Babesia spp. with an average 18S rRNA copy number of $370,472 / \mathrm{ml}$ whole blood (SD 659,438; range $72 \sim 199,552$ ). Melting point analysis and genomic sequencing showed four of the 10 dogs to be infected with $B$. gibsoni $\left(T_{\mathrm{m}} \sim 67^{\circ} \mathrm{C}\right)$ and six with $B$. vogeli $\left(T_{\mathrm{m}} \sim 58^{\circ} \mathrm{C}\right)$. None of the dogs were infected with both species or with $B$. vogeli or $B$. rossi. B. gibsoni is 
found in northern Africa, southern Asia, Australia, Europe, the USA and the Caribbean [17] and ours is the first report of the organism in Central America. The organism is thought to be transmitted by fighting or by ticks, in particular $R$. sanguineus group [38]. There are no reported human infections [39] but in dogs infections usually result in acute signs including fever, pallor, splenomegaly and anorexia [39]. Dogs that recover from the acute infection generally become chronic subclinical carriers with significantly reduced platelet counts [40]. Diagnosis is by detecting organisms in stained blood smears but in chronic cases organisms are seldom seen and serology or PCR are needed [39]. As with canine ehrlichiosis, treatment of $B$. gibsoni is difficult and often the parasite is not eliminated [41].

The other Babesia spp. we detected, B. vogeli, has been reported from Central America with 8\% of 146 dogs studied in Costa Rica being positive [8]. This organism is transmitted by $R$. sanguineus group, with infections being subclinical or causing only mild signs with anemia and thrombocytopenia [4]. It has also not been reported to infect people [38].

Only a few dogs $(5 / 39,13 \%)$ carried $A$. platys DNA with an average of 370,472 copies of the $16 \mathrm{~S}$ rRNA gene $/ \mathrm{ml}$ whole blood (SD 659,438; range $651 \sim 1,534,409$ ). This is similar to the prevalence reported in Costa Rica (14/146: $10 \%)$ [8] and indicates the organism is probably widely distributed in Central America, as it is elsewhere in the world. A. platys is probably transmitted by $R$. sanguineus group and is the agent of infectious canine cyclic thrombocytopenia [42]. There is only a single report of an infection in a person [43]. Although infections in dogs are often subclinical, infected dogs might be thrombocytopenic. Platelet numbers might be lower with coinfections with other vector-borne agents, in particular $E$. canis and Babesia spp. [17,44]. Although organisms can be seen in peripheral blood smears, the most sensitive diagnosis is by serology or PCR [42]. Treatment with doxycycline has been reported to sterilize infections [45].

The least common agent we detected was $R$. felis $(2 / 39$, $5 \%$ ) with gltA copies of 116 and $292 / \mathrm{ml}$ of whole blood (SD 125; range $116 \sim 292$ ). This is an emerging pathogen principally associated with cat fleas (Ctenocephalides felis) and responsible for flea-borne spotted fever in people [46]. The organism occurs on all continents except Antarctica and has been reported in cat fleas from Guatemala, Costa Rica and Panama in Central America $[9,47,48]$. Recent evidence has indicated dogs might be reservoir hosts for the organism although infections seem to be subclinical [14]. Infections in people can cause clinical signs, which are generally mild and consist of fever, headache, myalgia and rash [49]. In Africa, infections appear common with up to $6 \%$ of febrile patients in Kenya and Senegal reported to be PCR positive for the organism [50]. Although no clinical cases have been reported from Central America, $R$. felis appears to be widespread in the area and health workers should be aware of the possibility of flea-borne spotted fever in patients with a history of contact with fleas.

In the $80 \%(31 / 39)$ of dogs we studied which had DNA of a vector-borne agent, mixed infections were very common with 11 (28\%) having evidence of two agents, 3 (8\%) having evidence of three, and $4(10 \%)$ of four agents (Table 1). The most common multiple infection was with $H$. canis and E. canis (7 dogs) with infections with $H$. canis, E. canis, B. vogeli and A. platys being second most common (3 dogs). There is little detailed data on mixed infections and how one agent may exacerbate $[8,17,44]$ or ameliorate [51] the effects of another, which greatly complicated clinical diagnoses. Also it means that in many dogs multiple drug therapies are needed to cure animals and resolve hematological and biochemical abnormalities.

It is particularly noteworthy that many of the pathogens we found cause thrombocytopenia in apparently healthy dogs. The infections are often difficult to diagnose without expensive serology and/or PCR, and treatment is often unsuccessful which poses major problems to local veterinarians carrying out surgeries and organizations carrying out neutering programs in underprivileged areas. Finding innovative and inexpensive methods for parasite and vector control on dogs appears to be the best way forward for controlling these vector-borne pathogens of dogs and people.

The nucleotide sequences of the PCR amplicons we obtained for the five vector-borne pathogens we detected were identical to those reported previously. The sequences of the R. felis, B. gibsoni, B. vogeli, H. canis, A. platys and E. canis amplicons were the same as those reported in GenBank for organisms from Brazil (Gene Accession \#JF694092), St. Kitts (JX112784), St Kitts (JX112785), Brazil (KF692040), South Africa (KC189854) and the Czech Republic (KC479024), respectively.

Comparisons of the average gene copy numbers of the five vector-borne pathogens we studied showed the rRNA copy numbers for $E$. canis were significantly lower than those for H. canis, B. canis and A. platys (Figure 1; Kruskal-Wallis non-parametric ANOVA). This probably reflects the fact that $E$. canis occurs in monocytes which are in lower concentrations in the blood than neutrophils, erythrocytes and platelets in which the other organisms are found, respectively. The gltA copy number for $R$. felis was not significantly different from the rRNA copy number of the other four tick-borne agents.

\section{Conclusions}

Our study has added to the scant data on canine and zoonotic vector-borne agents in Central America. We 
Table 1 Prevalences of vector-borne agents in dogs determined by quantitative PCRs

\begin{tabular}{|c|c|c|c|c|c|}
\hline \multirow{2}{*}{$\begin{array}{l}\text { Dog } \\
\text { number }\end{array}$} & \multicolumn{5}{|c|}{ Tick-borne pathogens } \\
\hline & Rickettsia & Hepatozoon & Babesia & Anaplasma & Ehrlichia \\
\hline 1 & - & H. canis & B. vogeli & A. platys & E. canis \\
\hline 2 & - & - & - & - & E. canis \\
\hline 3 & - & - & - & - & - \\
\hline 4 & - & - & B. gibsoni & A. platys & E. canis \\
\hline 5 & - & - & B. gibsoni & - & - \\
\hline 6 & - & - & B. vogeli & - & E. canis \\
\hline 7 & - & H. canis & - & - & E. canis \\
\hline 8 & - & - & - & - & - \\
\hline 9 & - & - & - & - & E. canis \\
\hline 10 & - & H. canis & - & - & - \\
\hline 11 & - & H. canis & - & - & E. canis \\
\hline 12 & R. felis & - & - & - & E. canis \\
\hline 13 & - & H. canis & - & - & E. canis \\
\hline 14 & - & - & - & - & E. canis \\
\hline 15 & - & - & - & - & - \\
\hline 16 & - & H. canis & - & - & E. canis \\
\hline 17 & - & - & - & - & - \\
\hline 18 & - & - & - & - & E. canis \\
\hline 19 & - & - & - & - & - \\
\hline 20 & - & H. canis & B. vogeli & A. platys & E. canis \\
\hline 21 & - & H. canis & - & A. platys & - \\
\hline 22 & - & - & - & - & E. canis \\
\hline 23 & - & - & - & - & - \\
\hline 24 & - & H. canis & B. vogeli & A. platys & E. canis \\
\hline 25 & - & H. canis & B. vogeli & - & E. canis \\
\hline 26 & - & - & - & - & - \\
\hline 27 & - & - & - & - & - \\
\hline 28 & - & H. canis & - & - & E. canis \\
\hline 29 & - & H. canis & - & - & - \\
\hline 30 & - & H. canis & - & - & - \\
\hline 31 & - & H. canis & B. gibsoni & - & - \\
\hline 32 & - & H. canis & - & - & - \\
\hline 33 & - & H. canis & - & - & E. canis \\
\hline 34 & - & - & - & - & - \\
\hline 35 & - & H. canis & B. gibsoni & - & E. canis \\
\hline 36 & - & - & - & - & E. canis \\
\hline 37 & R. felis & H. canis & B. vogeli & - & E. canis \\
\hline 38 & - & H. canis & - & - & - \\
\hline 39 & - & H. canis & - & - & E. canis \\
\hline
\end{tabular}

"-"denotes the absence of examined DNA in the whole blood of the designated dog. provide the first data on these organisms in dogs in Nicaragua and the first report of B. gibsoni in Central America. The available data from our study and the few others performed in the region suggest vector-borne diseases of dogs are common and widespread and in need of further investigation. Also, many of the pathogens can infect people and health workers need to be aware of this possibility, particularly in patients that have contact with dogs and their parasites.

\section{Abbreviations}

HMBS: Hydroxymethylbilane synthase; VIDA: Intercultural and Definitive Adventure; R.: Rickettsia; B.: Babesia; H.: Hepatozoon; A.: Anaplasma; E.: Ehrlichia; C.: Coxiella; D.: Dirofilaria; R.: Rhipicephalus.

\section{Competing interests}

The authors have declared no conflict of interests.

\section{Authors' contributions}

LW, PK, BK and CW designed the experiment, monitored the study and interpreted the results. LW, KA, JZ and HSE performed the experiment. All authors read and approved the final version of the manuscript.

\section{Acknowledgments}

This project was supported by grants from the National Natural Science Foundation of China (NO: 31272575), the Ross University School of Veterinary Medicine and the Molecular Diagnostic Laboratory of Auburn University College of Veterinary Medicine. The authors sincerely appreciate the Intercultural and Definitive Adventure (VIDA) in sample collection for this study, and Xiaojing Zhu, Yongpeng Zhang and Lei Jiang from Yangzhou University College of Veterinary Medicine for their technical help.

\section{Author details}

'Yangzhou University College of Veterinary Medicine, Yangzhou, Jiangsu, P. R. China. ${ }^{2}$ Jiangsu Co-innovation Center for the Prevention and Control of Important Animal Infectious Diseases and Zoonoses, Yangzhou, Jiangsu, P. R. China. ${ }^{3}$ Ross University School of Veterinary Medicine, Basseterre, St. Kitts and Nevis. ${ }^{4}$ Faculty of Veterinary Medicine, Suez Canal University, Ismailia Egypt.

${ }^{5}$ Auburn University College of Veterinary Medicine, Auburn, Al, USA.

Received: 26 January 2014 Accepted: 10 March 2014

Published: 25 March 2014

\section{References}

1. Groves MG, Dennis GL, Amyx HL, Huxsoll DL: Transmission of Ehrlichia canis to dogs by ticks (Rhipicephalus sanguineus). Am J Vet Res 1975, 36:937-940

2. Harrus $\mathrm{S}$, Waner T: Diagnosis of canine monocytotropic ehrlichiosis (Ehrlichia canis): an overview. Vet J 2011, 187:292-296.

3. O'Dwyer LH: Brazilian canine hepatozoonosis. Rev Bras Parasitol Vet 2011, 20:181-193.

4. Solano-Gallego L, Baneth G: Babesiosis in dogs and cats-expanding parasitological and clinical spectra. Vet Parasitol 2011, 181:48-60.

5. Cardoso Cardoso L, Mendão C, Madeira De Carvalho L: Prevalence of Dirofilaria immitis, Ehrlichia canis, Borrelia burgdorferi sensu lato, Anaplasma spp. and Leishmania infantum in apparently healthy and CVBD-suspect dogs in Portugal-a national serological study. Parasit Vectors 2012, 5:62.

6. Romero LE, Meneses Al, Salazar L, Jiménez M, Romero JJ, Aguiar DM, Labruna MB, Dolz G: First isolation and molecular characterization of Ehrlichia canis in Costa Rica, Central America. Res Vet Sci 2011, 91:95-97.

7. Scorza AV, Duncan C, Miles L, Lappin MR: Prevalence of selected zoonotic and vector-borne agents in dogs and cats in Costa Rica. Vet Parasitol 2011, 183:178-183.

8. Rojas A, Rojas D, Montenegro V, Gutiérrez R, Yasur-Landau D, Baneth G, Vector-borne pathogens in dogs from Costa Rica: First molecular description of Babesia vogeli and Hepatozoon canis infections with a high prevalence of monocytic ehrlichiosis and the manifestations of co-infection. Vet Parasitol 2014, 199:121-128. 
9. Bermúdez CS, Zaldívar AY, Spolidorio MG, Moraes-Filho J, Miranda RJ, Caballero CM, Mendoza Y, Labruna MB: Rickettsial infection in domestic mammals and their ectoparasites in El Valle de Antón, Coclé, Panamá. Vet Parasitol 2011, 177:134-138.

10. Pineda V, Saldaña A, Monfante I, Santamaría A, Gottdenker NL, Yabsley MJ, Rapoport G, Calzada JE: Prevalence of trypanosome infections in dogs from Chagas disease endemic regions in Panama, Central America. Vet Parasitol 2011, 178:360-363.

11. Herrer A, Christensen HA: Natural cutaneous leishmaniasis among dogs in Panama. Am J Trop Med Hyg 1976, 25:59-63.

12. Ryan PR, Arana BA, Ryan JR, Wirtz RA, Wortmann GW, Rizzo NR: The domestic dog, a potential reservoir for Leishmania in the Peten region of Guatemala. Vet Parasitol 2003, 115:1-7.

13. Zhang J, Wei L, Kelly P, Freeman M, Jaegerson K, Gong J, Xu B, Pan Z, Xu C, Wang C: Detection of Salmonella spp. Using a Generic and Differential FRET-PCR. PLOS One 2013, 8:e76053.

14. Hii SF, Abdad MY, Kopp SR, Stenos J, Rees RL, Traub RJ: Seroprevalence and risk factors for Rickettsia felis exposure in dogs from Southeast Queensland and the Northern Territory, Australia. Parasit Vectors 2013, 6:159.

15. Wang C, Ahluwalia SK, Li Y, Gao D, Poudel A, Chowdhury E, Boudreaux MK, Kaltenboeck B: Frequency and therapy monitoring of canine Babesia spp. infection by high-resolution melting curve quantitative FRET-PCR. Vet Parasitol 2010, 168:11-18.

16. Li Y, Wang C, Allen KE, Little SE, Ahluwalia SK, Gao D, Macintire DK, Blagburn BL, Kaltenboeck B: Diagnosis of canine Hepatozoon spp. infection by quantitative PCR. Vet Parasitol 2008, 157:50-58.

17. Kelly PJ, Xu C, Lucas H, Loftis A, Abete J, Zeoli F, Stevens A, Jaegersen K, Ackerson K, Gessner A, Kaltenboeck B, Wang C: Ehrlichiosis, babesiosis, anaplasmosis and hepatozoonosis in dogs from St. Kitts, West Indies. Plos One 2013, 8:e53450

18. Berri M, Rekiki A, Boumedine KS, Rodolakis A: Simultaneous differential detection of Chlamydophila abortus, Chlamydophila pecorum and Coxiella burnetii from aborted ruminant's clinical samples using multiplex PCR. BMC Microbiol 2009, 9:130.

19. Wang C, Mount J, Butler J, Gao D, Jung E, Blagburn BL, Kaltenboeck B: Real-time PCR of the mammalian hydroxymethylbilane synthase (HMBS) gene for analysis of flea (Ctenocephalides felis) feeding patterns on dogs. Parasit Vectors 2012, 5:4.

20. McCall JW, Genchi C, Kramer LH, Guerrero J, Venco L: Heartworm disease in animals and humans. Adv Parasitol 2008, 66:193-285.

21. Levy JK, Lappin MR, Glaser AL, Birkenheuer AJ, Anderson TC, Edinboro CH: Prevalence of infectious diseases in cats and dogs rescued following Hurricane Katrina. J Am Vet Med Assoc 2011, 238:311-317.

22. Cutler SJ, Bouzid M, Cutler RR: Q fever. J Infect 2007, 54:313-318.

23. Marrie TJ, Durant H, Williams JC: Exposure to parturient cats: a risk factor for acquisition of Q fever in Maritime Canada. J Infect Dis 1988, 158:101-108.

24. Buhariwalla F, Cann B, Marrie TJ: A dog-related outbreak of Q fever. Clin Infect Dis 1996, 23:753-755.

25. Hornok S, Dénes B, Meli ML, Tánczos B, Fekete L, Gyuranecz M, de la Fuente J, De Mera IG, Farkas R, Hofmann-Lehmann R: Non-pet dogs as sentinels and potential synanthropic reservoirs of tick-borne and zoonotic bacteria. Vet Microbio/ 2013, 167:700-703.

26. Kelly PJ: Canine ehrlichioses: an update. J S Afr Vet Assoc 2000, 71:77-86.

27. Shaw SE, Day MJ, Birtles RJ, Breitschwerdt EB: Tick-borne infectious diseases of dogs. Trends Parasitol 2001, 17:74-80.

28. Dantas-Torres F: The brown dog tick, Rhipicephalus sanguineus (Latreille, 1806) (Acari: Ixodidae): from taxonomy to control. Vet Parasitol 2008, 152:173-185.

29. Bartsch RC, Greene RT: Post-therapy antibody titers in dogs with ehrlichiosis: follow-up study on 68 patients treated primarily with tetracycline and/or doxycycline. J Vet Intern Med 1996, 10:271-274.

30. Perez M, Bodor M, Zhang C, Xiong Q, Rikihisa Y: Human infection with Ehrlichia canis accompanied by clinical signs in Venezuela. Ann N Y Acad Sci 2006, 1078:110-117.

31. Troyo A, Calderón-Arguedas O, Alvarado G, Vargas-Castro LE, Avendaño A: Ectoparasites of dogs in home environments on the Caribbean slope of Costa Rica. Rev Bras Parasitol Vet 2012, 21:179-183.
32. Baneth G, Samish M, Shkap V: Life cycle of Hepatozoon canis (Apicomplexa: Adeleorina: Hepatozoidae) in the tick Rhipicephalus sanguineus and domestic dog (Canis familiaris). J Parasitol 2007, 93:283-299.

33. Baneth G: Perspectives on canine and feline hepatozoonosis. Vet Parasitol 2011, 181:3-11.

34. Pasa S, Voyvoda H, Karagenc T, Atasoy A, Gazyagci S: Failure of combination therapy with imidocarb dipropionate and toltrazuril to clear Hepatozoon canis infection in dogs. Parasitol Res 2011, 109:919-926.

35. Homer MJ, Aguilar-Delfin I, Telford SR 3rd, Krause PJ, Persing DH: Babesiosis. Clin Microbiol Rev 2000, 13:451-469.

36. Irwin PJ: Canine babesiosis: from molecular taxonomy to control. Parasit Vectors 2009, 2(Suppl 1):S4

37. Taboada J, Lobetti R: Babesiosis. In Infectious Diseases of the Dog and Cat. Edited by Greene CE. Missouri: Saunders Elsevier; 2006:722-736.

38. Esch KJ, Petersen CA: Transmission and epidemiology of zoonotic protozoal diseases of companion animals. Clin Microbiol Rev 2013, 26:58-85.

39. Ayoob AL, Hackner SG, Prittie: J clinical management of canine babesiosis. J Vet Emerg Crit Care (San Antonio) 2010, 20:77-89.

40. Matsuu A, Kawabe A, Koshida Y, Ikadai H, Okano S, Higuchi S: Incidence of canine Babesia gibsoni infection and subclinical infection among Tosa dogs in Aomori Prefecture. Japan J Vet Med Sci 2004, 66:893-897.

41. Iguchi $A$, Matsuu A, Fujii $Y$, Ikadai $H$, Hikasa $Y$ : The in vitro interactions and in vivo efficacy of atovaquone and proguanil against Babesia gibsoni infection in dogs. Vet Parasitol 2013, 197:527-533.

42. Alleman AR, Wamsley HL: An update on anaplasmosis in dogs. Vet Med 2008, 103:212-220.

43. Maggi RG, Mascarelli PE, Havenga LN, Naidoo V, Breitschwerdt EB: Coinfection with Anaplasma platys, Bartonella henselae and Candidatus Mycoplasma haematoparvum in a veterinarian. Parasit Vectors 2013, 6:103.

44. Brown GK, Canfield PJ, Dunstan RH, Roberts TK, Martin AR, Brown CS, Irving R: Detection of Anaplasma platys and Babesia canis vogeli and their impact on platelet numbers in free-roaming dogs associated with remote Aboriginal communities in Australia. Aust Vet J 2006, 84:321-325.

45. Chang WL, Su WL, Pan MJ: Two-step PCR in the evaluation of antibiotic treatment for Ehrlichia platys infection. J Vet Med Sci 1997, 59:849-851.

46. Abdad M, Stenos J, Graves S: Rickettsia felis, an emerging flea-transmitted human pathogen. Emerg Health Threats J 2011, 4:7168.

47. Hun L, Troyo A, Taylor L, Barbieri AM, Labruna MB: First report of the isolation and molecular characterization of Rickettsia amblyommii and Rickettsia felis in Central America. Vector Borne Zoonotic Dis 2011 11:1395-1397.

48. Troyo A, Álvarez D, Taylor L, Abdalla G, Calderón-Arguedas Ó, Zambrano ML Dasch GA, Lindblade K, Hun L, Eremeeva ME, Estévez A: Rickettsia felis in Ctenocephalides felis from Guatemala and Costa Rica. Am J Trop Med Hyg 2012, 86:1054-1056.

49. Pérez-Osorio CE, Zavala-Velázquez JE, Arias León JJ, Zavala-Castro JE: Rickettsia felis as emergent global threat for humans. Emerg Infect Dis 2008, 14:1019-1023.

50. Richards AL, Ju J, Sylvia O, Ryan D, Khalif A, Abdile A, Sharif SK, Feikin DR, Breiman RF, Kariuki Njenga M: Human Infection with Rickettsia felis, Kenya. Emerg Infect Dis 2010, 16:1081-1086.

51. Matthewman LA, Kelly PJ, Bobade PA, Tagwira M, Mason PR, Majok A, Brouqui P, Raoult D: Infections with Babesia canis and Ehrlichia canis in dogs in Zimbabwe. Vet Rec 1993, 133:344-346.

doi:10.1186/1756-3305-7-126

Cite this article as: Wei et al:: First report of Babesia gibsoni in Central America and survey for vector-borne infections in dogs from Nicaragua. Parasites \& Vectors 2014 7:126. 